\title{
Mozart Effect and Its Clinical Applications: A Review
}

\author{
W. Verrusio ${ }^{1 *}$, F. Moscucci ${ }^{1}$, M. Cacciafesta ${ }^{1}$ and N. Gueli ${ }^{1}$ \\ ${ }^{1}$ Department of Cardiovascular, Respiratory, Nephrological, Anesthesiologic and Geriatric Sciences, \\ Sapienza University of Rome, Viale del Policlinico 155, 00161 Roma, Italy.
}

\begin{abstract}
Authors' contributions
The work was carried out in collaboration between all authors. Authors WV and FM have reviewed literature searches and they wrote the manuscript. All authors read and approved the final manuscript.

Article Information

DOI: 10.9734/BJMMR/2015/17192 Editor(s):

(1) Thomas I. Nathaniel, Center for Natural and Health Sciences, Marywood University, PA, USA.

Reviewers:

(1) Anonymous, Northeastern University, USA (2) Casselman Filip, Department of Cardiovascular and Thoracic Surgery, OLV Clinic, Aalst, Belgium. (3) Anonymous, USA

(4) Alfonso Ceccherini-Nelli, Alberta Hospital Edmonton, Canada. Complete Peer review History: http://www. sciencedomain.org/review-history.php?iid=1120\&id=12\&aid=9307
\end{abstract}

Review Article

Received $2^{\text {nd }}$ March 2015

Accepted $2^{\text {nd }}$ May 2015

Published $19^{\text {th }}$ May 2015

ABSTRACT

Recent research efforts examining the effects on the brain of listening to music have discovered that music, with specific characteristics, is able to improve cognitive and learning capacity. Recent studies have demonstrated that music, in particular some musical compositions (such as those of W. A. Mozart and J. S. Bach), has a notable role not only in cognitive disturbances, but also in the treatment of several syndromes and diseases, either by rehabilitating or by stimulating cerebral synaptic plasticity. The Mozart Effect was described for the first time in 1993. Subsequently, other studies with similar designs were made. This review summarizes the recent scientific literature on the Mozart Effect. More studies are needed, in order to define specific protocols in which music helps clinicians in recuperating patients and in improving their quality of life.

Keywords: Music; Mozart effect; cognitive capacity; Pleiotropic effects; quality of life.

\section{INTRODUCTION}

Music has had a notable role in human history: not only as art expression but also as a means of communication. The discovery of a 35.000 year old flute demonstrates that music has existed since pre-historic times [1]. In recent times, music has played different and interesting parts: 
in the context of surgery, as modulator of anxiety before anesthesia in surgical procedures [2]; as immune-modulator, in particular in the regulation of interleukin 6, dehydroepiandrosterone and epinephrine production [3]; as instrument of training in people with cognitive impairment [4]. Recent studies have demonstrated that some kinds of music could have a strong impact in improving and ameliorating different health status. The effects of music on the cardiovascular system and on cardiovascular health were recently investigated [5]. In this study, heart rate and the cerebral blood flow were influenced by listening to music with specific mathematical characteristics. In addition, it was reported that relaxing music significantly decreases the level of anxiety of patients in a preoperative setting even compared to orally administered midazolam. Moreover, the author stated that after 30 minutes of bed rest, there was a significant difference in cortisol levels between the music and the non- music group. That effect has been increased with vocal and orchestral music, which produced better correlations between cardiovascular or respiratory signals compared with a more uniform emphasis. Beneficial effect of music on pain, anxiety, mood and quality of life was also shown in people with cancer [6].

Some studies have shown that music may strengthen cortical activity, improving other cerebral functions and EEG registration and $\mathrm{fMRI}$ could demonstrate specific patterns $[7,8]$. This effect seems to be linked to specific musical compositions (such as those of W. A. Mozart and J. S. Bach), whose characteristics should be able to stimulate cognitive functions and neuroplastic mechanisms. Thus, some authors have studied a phenomenon known as "Mozart Effect" (ME): an enhancement of performance or change in neurophysiological activity associated with listening to Mozart's music. The ME was described for the first time by Rauscher et al. in a study in which they had demonstrated that students who had listened to Mozart's music (sonata for two pianos in D major K. 448) obtained IQ scores 8-9 points higher in a spatial reasoning test (from Stanford-Binet test) compared with those who had listened to relaxation instructions or silence [9]. This evidence showed that the ME was specially able to improve spatial-temporal functions. On the other hand, performance in spatial-temporal skills may be affected by differences in arousal and mood [10]. Another author circumscribed the ME just for the spatial tasks and underlined that this effect was not limited to Mozart's music, but confirmed that not all types of music can produce it [11].

It is well known that, from its birth to now, ME has been experimented in many studies, with contrasting results. These evidences have led to deny its very existence.

Thus, can we state that ME really exists? If so, can it be used with medical and therapeutic purposes?

The aim of this review is:

1. Seeking for studies which support ME existence and its possible medical uses;

2. Analyzing studies which deny ME existence;

3. Looking for the most recent studies that investigate the neurophysiological bases of $\mathrm{ME}$ and its therapeutic effects.

\section{METHODS}

In this review we have analyzed 54 articles, shown in Table 1. The database used for the research was Pubmed/Medline.

The following inclusion criteria were considered:

1) Studies: Case control, review, observational study, metanalysis, clinical trial, commentary, case report, review, book. Studies were eligible only if they were published as full paper.

2) Participants: In this review studies on humans (men, women and children) and on animals were considered.

3) Topics: We focused our attention on ME and its effects on health, learning processes and recent findings.

\section{RESULTS}

We have analyzed the results of articles supporting the role of ME in different medical conditions. Articles which deny the ME existence itself or restrict its importance, were included and analyzed.

\subsection{Studies PRO}

\subsubsection{ME and spatial and temporal skills}

Rauscher demonstrated this effect in a study in which separate groups of rats were exposed, in 
utero followed by a postpartum period of 60 days, to Mozart's piano sonata K448, to minimalist music by the composer Philip Glass, to white noise or to silence and then tested for their ability to negotiate a maze. The Mozart group completed the maze test significantly more quickly and with fewer errors $(P<0.01)$ than the other three groups; thus, enjoyment and musical appreciation is unlikely to have been the basis of the improvement [12].

In a study [13] an animal model of ME has been established. Mice's ability to negotiate a maze was analyzed. Two groups of mice were continuously exposed to music (Group I: Mozart's Sonata K.448, Group II: Beethoven's Fur Elise), and after a 10 week period music exposure for 10 hours, the mice were tested in the maze, recording working time in maze and number of errors. The same procedure was adopted for other two groups of mice, just exposing them periodically to music $(58 \%$ silence). As a result, the Mozart group exhibited significant enhancement compared with the control mice in both parts of the study; in particular spending less time and committing fewer errors in completing the maze test.

But what can the results be when people with cognitive impairment undergo stimulation?

A study investigated the enhancement of scores on spatial-temporal tasks after listening to Mozart condition in a set of twins only one of who suffered from Alzheimer's disease (AD). After listening to an excerpt from the sonata for two pianos in D major (K.448), the one with $A D$ showed considerable improvement on spatialtemporal skills when compared with pretest scores. No improvement was detected in the psychometric performance of the healthy twin [14].

In a recent study we tested the Mozart Effect (ME) in elderly patients with Mild Cognitive Impairment $(\mathrm{MCl})$. Spatial-temporal skills were assessed in twelve individuals using a series of tests, both prior to and following musical exposure to Mozart's K488. The results obtained showed a significant improvement in the PaperFolding and Cutting Test (PF \& C) and in the Rey's 15 Words Test after listening to Mozart's composition. The same patients underwent assessment using the same series of tests after fifteen days and after having listened to Beethoven's "Fur Elise". However, the results did not highlight any improvement in the performance of cognitive tasks. We then distributed to ten of the patients in question a CD featuring a recording of $\mathrm{K} 488$ to be listened to on a daily basis for six months. At the end of this period, all the individuals showed an improvement in the PF \& C Test during the first part of the assessment, i.e. prior to listening to $\mathrm{K} 448$, thus proving a chronic effect of the ME provided that stimulation is maintained over a period of time. Therefore, we concluded that listening to certain types of music can have a positive and reproducible effect on specific cognitive functions, including in individuals suffering from $\mathrm{MCl}$ [4].

Some Authors had collected EEG registrations during neuropsychological tests, in people who were or were not listening Mozart music. Data obtained demonstrated that this music can switch off some cerebral areas connected to stress and "re-organize" other areas of right hemisphere, promoting spatial-temporal performances $[15,16]$. Moreover, listening to this music produces a significant improvement in beta spectrum in EEG, positively related to regional cerebral blood flow in the reaching precuneus and prefrontal cortex [17].

Bodner et al. [18] using fMRI, showed that the sonata for two pianos K. 448 improved the blood flow not only in temporal cortex (such as "For Elisa" of L.van Beethoven or other pieces for piano of 1930s), but also in prefrontalfrontolateral cortex, occipital cortex and in cerebellum, regions related to spatial and temporal functions.

The temporal dimension of ME was investigated by Ho et al. [19] who provided the first empirical demonstration supporting the existence of a purely temporal component to the $M E$ using a non-spatial visual attentional blink $(A B)$ task: in fact, participants were able to detect the second target of the test significantly more accurately in the $A B$ stream when Mozart sonata was played normally, than when the sonata was played in reverse or while silence.

\subsubsection{ME and other different fields of interest}

Mozart's sonata could provide an improvement in pain and stress. Measure du Stress Psychologique (MSP) and Visual Analogue Scale (VAS) were administered to patients with tinnitus. After a single exposure to Mozart's sonata K.448, the MSP and VAS results demonstrated a significant reduction in stress and pain feelings [20]. 
Another application was found by Salvatore et al. who used ME to maintain visual performance in a patient with macular pucker and glaucoma [21]. The patient underwent visual rehabilitation with acoustic biofeedback by means of the MAIATM Vision Training Module, 10 minutes for each eye once a week for 5 weeks. The patient was asked to move his eyes according to a sound which changed into Mozart's Sonata K.448 when he locked the fixation target. Visual acuity, fixation stability improved and the patient was really satisfied with the training. The author have demonstrated that music could enhance synaptic plasticity and affect neural learning and fixation training, improving visual performance in this patient with macular pucker, postponing surgical time and ameliorating the quality of life.

Even in preterm infants, ME seems to produce beneficial effects. Lubetzky $R$ et al. [22] observed that the rate of weight gain in preterm infants who are exposed to music seems to improve with a reduction of resting energy expenditure (REE). They performed a prospective, randomized clinical trial with crossover in 20 healthy, appropriate-weight-for-gestational-age, gavagefed preterm infants. Infants were randomly assigned to be exposed to a 30-minute period of Mozart music or no music on 2 consecutive days. Metabolic measurements were performed by indirect calorimetry. REE was similar during the first 10-minute period of both randomization groups. During the next 10-minute period, infants who were exposed to music had a significantly lower REE than when not exposed to music $(P=.028)$. This was also true during the third 10minute period $(P=.03)$. Thus, on average, the effect of music on REE is a reduction of approximately $10 \%$ to $13 \%$ from baseline, an effect obtained within 10 to 30 minutes. All in all, exposure to Mozart music significantly lowers REE in healthy preterm infants. Thus, they speculate that this effect of music on REE might explain, in part, the improved weight gain that results from this "Mozart effect" [22].

\subsubsection{Mozart effect and epilepsy management}

In patients with epilepsy, Mozart's sonata could provide an improvement in symptoms [23,24]. The long-term effect of listening to Mozart K.448 has been shown in a group of children with epilepsy. They listened to the Sonata for two pianos for 8 minutes once a day before bedtime for a six-month-period. At the end of the study all patients, except those with occipital discharges, showed a significant decrease in epileptiform discharges. A recent meta-analyses (12 studies) confirms a significant decrease in interictal epileptic discharges in patients listening to Mozart's music [25].

In a study of Huges JR et al. [26] tested ME, using the Piano Sonata in D Major (K.448), examining patients with seizures. In 23 of 29 instances significant decreases in epileptiform activity were noted from patients even in coma, with status epilepticus or with periodic lateralized epileptiform discharges (PLEDs). The effect may be immediate or require $40-300 \mathrm{sec}$ to manifest itself. The change in the amount of ictal activity in one patient in coma was from $62 \%$ before the music to $21 \%$ during Mozart. Amplitudes of these discharges also have often decreased. Examples of PLEDs on both temporal areas are shown in which the effect was only on the left temporal area but in other patients only on the right temporal area. Brain maps during the music showed theta and alpha activity decreased on the central areas, while delta waves increased on the frontal midline area. The basis of this effect is likely that the organization of the cerebral cortex with its highly structured radial columns seen throughout both hemispheres may resonate with the superior architecture of Mozart's music. In 2001 and 2002, Hughes JR emphasized the effect on epileptiform patterns $[27,28]$. According to his findings, ME shows a chronic effect over a period of 1-2 days, addresses the distinctive aspects of the music to account for this phenomenon and shows that long-term periodicity in the power of the music is a special quality. In his review, he speculate on the melodic line and showed that Mozart repeats the melodic line much more frequently than other well-known composers.

To determine whether this music could exert a longer effect, studies were conducted in an eightyear-old girl with a particularly intractable form of childhood epilepsy, the Lennox-Gastaut syndrome, with many drop attacks accompanied by bilateral spike and wave complexes and focal discharges from the right posterior temporal area [29]. Mozart's sonata was played every 10 minutes for each hour of the day when she was awake. At the end of the waking period the number of clinical seizures had fallen from 9 during the initial four hours to one during the last four hours and the number of seconds during which general discharges occurred fell from 317 to 178 . The following day the number of attacks was two in seven and half hours. 
Table 1. Articles analysed in this review and results

\begin{tabular}{|c|c|c|c|}
\hline Authors, year & Study & Topics & Results* \\
\hline Aoun P, et al. (2005) [13] & Case-control & ME and learning in mice & + \\
\hline Attanasio G, et al. (2013) [20] & Clinical trial & ME and tinnitus & + \\
\hline Bangerter A, Heath C (2004) [44] & Review & - & - \\
\hline Bodner M et al. (2001) [18] & Observational & Brain imaging enhancement & + \\
\hline Bradt J et al. (2011) [6] & Metanalysis & & + \\
\hline Cacciafesta M et al. (2010) [4] & $\begin{array}{l}\text { Clinical trial } \\
\text { (12 patients) }\end{array}$ & ME and cognitive impairment & + \\
\hline Dastgheib SS et al. (2014) 25] & Metanalysis & ME and epilepsy & + \\
\hline Frova A (2006) [46] & Book & - & + \\
\hline Fukui H, et al. (2008) [59] & - & ME and neurogenesis & + \\
\hline Fudin R, Lembessis E (2004) [30] & Commentary & - & - \\
\hline Gaser C, Schlaug G (2003) [58] & $\begin{array}{l}\text { Clinical trial } \\
\text { (40 patients) }\end{array}$ & ME in musicians and not & $\begin{array}{l}+ \text { in non } \\
\text { musicians }\end{array}$ \\
\hline Giannouli V et al. (2010) [38] & $\begin{array}{l}\text { Clinical trial } \\
\text { (24 patients) }\end{array}$ & $\begin{array}{l}\text { ME and reverse mnemonic } \\
\text { recall tasks }\end{array}$ & - \\
\hline Hetland L (2000) [11] & Commentary & - & + \\
\hline Ho C, et al. (2007) [19] & Clinical trial & ME and attentional blink task & + \\
\hline Hughes JR, et al. (1998) [26] & $\begin{array}{l}\text { Clinical trial } \\
\text { ( } 29 \text { patients) }\end{array}$ & ME and epilepsy & + \\
\hline Hughes JR, et al. (1999) [29] & Case report & ME and epilepsy & + \\
\hline Hughes JR, Find JJ (2000) [52] & l & - & + \\
\hline Hughes JR (2001) [27] & Review & - & + \\
\hline Hughes JR (2002) [28] & Review & - & + \\
\hline Jausovec N, et al. (2003) [8] & $\begin{array}{l}\text { Clinical trial } \\
\text { (56 patients) }\end{array}$ & ME, learning and EEG & + \\
\hline Jausovec N, et al. (2006) [15] & $\begin{array}{l}\text { Clinical trial } \\
\text { (56 patients) }\end{array}$ & ME and learning & + \\
\hline Jenkins JS (2001) [53] & Review & - & + \\
\hline Johnson JK, et al. (1998) [14] & $\begin{array}{l}\text { Case control } \\
\text { ( } 2 \text { patients) }\end{array}$ & ME and Alzheimer disease & + \\
\hline Keenan JP, et al. (2001) [57] & Clinical trial & ME and neuroimaging & l \\
\hline Lemmer B. (2008) [60] & Clinical trial & $\begin{array}{l}\mathrm{ME} \text { and blood pressure/heart } \\
\text { rate in rats }\end{array}$ & + \\
\hline Leng X and Shaw GL (1991) 45 & Commentary & - & + \\
\hline Lin LC, et al. (2011) [23] & $\begin{array}{l}\text { Clinical trial } \\
\text { (18 patients) }\end{array}$ & ME and epilepsy & + \\
\hline Lin LC, et al. (2011) [24] & $\begin{array}{l}\text { Clinical trial } \\
\text { (11 patients) }\end{array}$ & ME and epilepsy & - \\
\hline Lints A, Gadbois S (2003) [40] & Clinical trial & ME and spatial reasoning & - \\
\hline Lubetzky R (2010) [22] & $\begin{array}{l}\text { Clinical trial } \\
\text { (20 patients) }\end{array}$ & $\begin{array}{l}\text { ME and growth in preterm } \\
\text { infant }\end{array}$ & + \\
\hline $\begin{array}{l}\text { Masataka N, Perlovsky LI (2013) } \\
\text { [47] }\end{array}$ & $\begin{array}{l}\text { Clinical trial } \\
\text { (50patients) }\end{array}$ & ME and cognitive interference & + \\
\hline Perlovsky LI. (2013) [48] & Commentary & ME and cognitive dissonance & + \\
\hline $\begin{array}{l}\text { Masataka N, Perlovsky LI (2012) } \\
\text { [49] }\end{array}$ & $\begin{array}{l}\text { Clinical trial } \\
\text { (75 patients) }\end{array}$ & ME and cognitive dissonance & + \\
\hline Perlovsky L, et al. (2013) [50] & $\begin{array}{l}\text { Clinical trial } \\
\text { (64 patients) }\end{array}$ & ME and cognitive dissonance & + \\
\hline Pietschnig J, et al. (2010) [33] & Metanalysis & Existence of ME & - \\
\hline McCutcheon LE (2000) [35] & $\begin{array}{l}\text { Clinical trial } \\
\text { (36 patients) }\end{array}$ & ME and its generalized effect & - \\
\hline Nakamura S, et al. (1999) [17] & Clinical trial & ME and blood flow and EEG & l \\
\hline Newman J, et al. (1995) [39] & $\begin{array}{l}\text { Clinical trial } \\
\text { (114 patients) }\end{array}$ & ME and spatial ability & - \\
\hline
\end{tabular}


Table 1 continued......

\begin{tabular}{|c|c|c|c|}
\hline Rauscher FH, et al. (1998) [12] & Clinical trial & ME and maze learning in rats & + \\
\hline Rauscher FH, et al. (1995) [16] & Commentary & ME and neurobiological basis & + \\
\hline Rauscher FH, et al. (1993) [9] & Commentary & ME and spatial task & + \\
\hline Rideout BE (1999) [34] & Commentary & - & - \\
\hline Salvatore S, et al. (2011) [21] & Case report & ME and visual rehab. & + \\
\hline Schlaug G, et al. (2001) [54] & Review & - & I \\
\hline Schlaug G, et al. (1995) [55] & Observational & ME in musicians & I \\
\hline Schlaug G, et al. (1995) [56] & Observational & - & I \\
\hline Steele KM, et al. (1999) [31] & $\begin{array}{l}\text { Clinical trial } \\
\text { (206 subjects) }\end{array}$ & Failure to replicate ME & - \\
\hline Steele KM, et al. (1999) [32] & $\begin{array}{l}\text { Clinical trial } \\
\text { (125 subjects) }\end{array}$ & ME and mood & - \\
\hline Steele KM, (2000) [10] & Review & - & - \\
\hline $\begin{array}{l}\text { Talero-Gutiérrez C, et al. (2004) } \\
\text { [43] }\end{array}$ & Review & - & limited \\
\hline Thompson WF, et al. (2001) [36] & Clinical trial & ME and arousal and mood & - \\
\hline Tramo MJ, et al. (2001) [51] & Clinical trial & ME and theory of harmony & + \\
\hline Trappe HJ, (2010) [5] & Clinical trial & ME and Cardiovascular effects & + \\
\hline Twomey A, Esgate A (2002) [37] & $\begin{array}{l}\text { Clinical trial } \\
\text { (40 patients) }\end{array}$ & ME only in non musicians & - \\
\hline
\end{tabular}

\subsection{Studies CON}

\subsubsection{Mozart effect: artifact of arousal $/ \mathrm{mood}$ and publication bias}

Many other studies failed to replicate the Rauscher and Shaw findings [30].

Some doubts on the existence of ME have arisen with the Steele KM et al.'s study [31]. They stated that Rauscher and Shaw cited an unpublished study in which a verbal distractor was inserted between the pretest and listening condition, and the manipulation produced the recovery of a Mozart effect. Their experiment attempted to confirm the unpublished study. 206 college students were exposed to one of three sequences, pretest-Verbal distractor materialMozart, pretest-Mozart-Verbal distractor material, and pretest-Verbal distractor material. An immediate post-test indicated no significant difference on solution of paper folding and cutting items among the three groups. The results do not support Rauscher and Shaw, so their negative results are consistent with prior failures in other laboratories to produce a Mozart effect. In another study Steele KM affirmed that some investigators of the "Mozart effect" have not controlled for the influence of differences in arousal or mood induced by treatment conditions [32]. A meta-analysis on ME (nearly 40 studies, over 3000 subjects) highlighted how publication bias and, in studies with higher evidence to support ME, lab affiliation to
Rauscher and colleagues generated an overestimation of the existence of this phenomenon [33]. Studies by Ride out and colleagues reported differences in spatial reasoning after listening to a Mozart sonata compared against a relaxation instruction tape [34]. The conditions may have affected subjects' arousal differentially, with the sonata increasing arousal and the relaxation instructions decreasing arousal, which could have affected spatial reasoning performance. Evidence is cited in support of this suggestion and indicates the importance of analyzing the influence of arousal differences in Mozart effect research.

Another failure to generalize the ME existence came from McCutcheon LE [35]. He stated that Rauscher and Shaw performance is unlikely unless three conditions are met. His study was designed to meet those three conditions. 36 adults were exposed to one of six listening orders and one of six test orders. Listening and test orders had no systematic effect on spatial reasoning performance. A one-factor, repeatedmeasures analysis of variance yielded no significant difference on spatial reasoning performance after listening to classical music, jazz, or silence. A reanalysis, using only those items most likely to tap spatial reasoning, fell short of significance, and mean scores were in the direction opposite to that hypothesized. These results were inconsistent with studies that have supported a Mozart effect. 
The artifact underlying ME was also assumed by Thompson WF et al. [36]. In their study they have examined whether the Mozart effect is a consequence of between-condition differences in arousal and mood. All participants completed a test of spatial abilities after listening to music or sitting in silence. The music was a Mozart sonata (a pleasant and energetic piece) for some participants and an Albinoni adagio (a slow, sad piece) for others. They also measured enjoyment, arousal, and mood. Performance on the spatial task was better following the music than the silence condition but only for participants who heard Mozart. The two music selections also induced differential responding on the enjoyment, arousal and mood measures. Moreover, when such differences were held constant by statistical means, the Mozart effect disappeared. All in all, these findings, according to the authors, provide compelling evidence that the Mozart effect is an artifact of arousal and mood.

\subsubsection{Mozart effect, musical background and musical pleasure}

In 2002, Twomey A et al. investigated this phenomenon in 20 musicians and 20 nonmusicians [37]. The trion model predicts increased synchrony between musical and spatiotemporal centers in the right cerebral hemisphere. Since increased left-hemispheric involvement in music processing occurs as a result of music training, predictions deriving from the possibility of increased synchrony with lefthemispheric areas in musicians were tested, including improved performance on language as well as spatiotemporal tasks. They found that spatiotemporal, synonym generation, and rhyming word generation tasks were employed as was the Mozart Sonata K.448. A Mozart effect was demonstrated on the spatiotemporal task, and the facilitator effect of exposure to Mozart was greater for the nonmusician group. On the other hand, no Mozart effect was found for either group on the verbal tasks, although the musicians scored higher on rhyming word generation. The failure to induce a Mozart effect in the musician group on verbal tasks, as well as that group's limited facilitation on spatiotemporal tasks, according to the authors, may be associated with either a ceiling effect due to the long-term effects of music training or from methodological factors. The same findings have not been confirmed in Giannouli $V$ et al. study [38].
Musical background and training were important determinant of tests results also in Newman $\mathrm{J}$ et al. [39] study. In their study, 114 students were pretested on items from the Raven's Progressive Matrices-Advanced Form, then instructed to listen to either $8 \mathrm{~min}$. of Mozart's music, relaxation instructions, or silence. Then subjects were post-tested on an equivalent set of Raven's items. The subjects were also asked to provide information about their musical background and preferences. Subjects in all 3 treatment groups showed a practice effect, but this improvement in Raven's scores was not dependent on the type of treatment received.

Some authors [40] have shown that participants' spatial reasoning tasks is unlikely influenced by listening Mozart music, but also by a variety of conditions, not depending on participants' expectations. The effect of music on cognitive tasks may be influenced by genre preference of patients. In other words, that whether it's classical, pop, rock and roll or patient's favorite tunes, it's musical pleasure that offers benefits in task performance [41-42].

\subsubsection{Mozart effect: a "scientific legend"}

Reviewing the literature about ME, TaleroGutierrez C et al. found that the effects of exposure to music by Mozart (the 'Mozart effect') when they actually occurred were limited to a specific skill that did not last for more than a few minutes [43]. Formal musical education, on the other hand, shows more permanent positive effects but which can be attributed to the individual attention the pupil receives and to the stimulation in basic skills for general learning.

In 2004 Bangerter A et al. [44] reported three media studies of the diffusion of a scientific legend as a particular kind of shared belief. They analyzed the Mozart effect (ME), as means of intelligence enhancer. They supposed that some scientific hypothesis could be influenced by many bias, due to diffusion of partial and incorrect ideas about scientific problems. This assumption can be supported, according to the Authors to show that the ME elicited more persistent media attention than other science reports and this attention increased when the ME was manifested in events apart from science. Some studies suggested that diffusion of the ME may have responded to varying levels of collective anxiety, showing a content evolution during diffusion. The results provide evidence for the functionality of diffusion 
of ideas and initial elements for a model of the emergence and evolution of a "scientific legend", as the Authors stated.

\section{DISCUSSION}

According to these evidences, it seems obvious that there is not a clear position of the scientific community on this theme (Fig. 1).

Some authors have tried to explicate the underlying neurophysiologic basis of this phenomenon, looking for an objective and scientific approach.

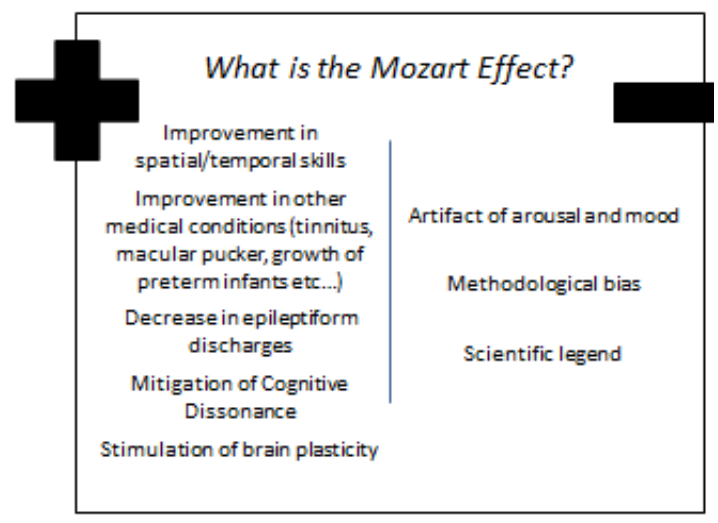

Fig. 1. The Mozart effect: hypothesis pro (+) and con (-)

Leng and Shaw proposed that music is a "prelanguage", which can enhance the cortex's ability to accomplish pattern development, thus improving other higher brain functions [45]. Rauscher et al. demonstrated a long term enhancement of non-verbal cognitive abilities in early life music training [16].

According to Frova, cerebral acoustic pathways have the same functions of an analog-to-digital converter, in which every information is the result of "counting". In fact, the brain is able to calculate temporally neuronal charges, which come from the inner ear; this ability produces consonance and the perception of an homogeneous tone. These signals are more comprehensible and easier to elaborate thanks to their characteristics [46]. Masataka and Perlovsky have demonstrated that consonant music can help to mitigate cognitive dissonance, a discomfort caused by holding conflicting cognitions simultaneously [47]. The resolution of cognitive dissonance consists in discarding contradictions but this process may to devaluate and discard new knowledge [48]. The sonata for two pianos K448 presents simple melodic elements and rare dissonances that fuel the perception simplicity which characterizes the entire movement. Thus the exposure to Mozart's music may exert a strong positive influence upon the performance of tests by reconciling the cognitive dissonance [49] and increasing the duration during which participants can tolerate stressful conditions while evaluating test choices [50]. It has been demonstrated that classical theory of tonal harmony reflects the physiological and anatomical properties of the auditory nervous system, giving it a neurophysiological basis. It was demonstrated that there is improvement in cognitive abilities immediately after listening to K.448 sonata and other compositions with the same time period index [51]. One of the distinctive features of Mozart's music is the frequent repetition of the melodic line; this determines the virtual lack of "surprise" elements that may distract the listener's attention from rational listening, where each element of harmonic (and melodic) tension finds a resolution that confirms listeners' expectations. The authors advanced the theory that said time periods are in keeping with a general theme that is a characteristic of Mozart's music, which is highly organized, presumably echoing the organization of the cerebral cortex. The physical characteristics probably responsible for the Mozart effect lie on the high degree of long-term periodicity, especially within the 10-60 s range [52]. It is suggested that music with an high degree of long-term periodicity would resonate within the brain to decrease seizure activities [53].

These structural elements are found in other compositions: in fact the Mozart Effect also exists in pieces by Bach.

The reasons for these effects could lie in the gene expression that is stimulated by listening to this kind of music. Rauscher and her colleagues used rat in a study [9], which, like humans, perform better on learning and memory tests after listening to the sonata. The researchers found that more intelligent rats had increased gene expression of brain-derived neurotrophic factor (BDNF), a neural growth factor, cAMP response element-binding (CREB), a learning and memory compound, and synapsin I (SYN 1), a synaptic growth protein, in their hippocampus, as compared to control rats who had listened to equivalent amounts of white noise. 
Music should also have a role in neuroplasticity. It allows the brain to adapt to environmental factors that cannot be anticipated by genetic programming. Many studies have shown that years of musical experience, especially in those musicians who begin training early on, might lead to an increase in grey and white matter volume in several brain regions [54-58].

Some Authors proposed that music (not only Mozart's sonata), may facilitate the neurogenesis, regeneration and the repair of neurons [59]. They suggested that listening to music may determine these neuronal changes by adjusting the secretion of steroid hormones, leading to cerebral plasticity. Cortisol, testosterone and estrogen levels are influenced by listening to music, maybe regulating the receptor genes related to the hormonal responses, and connected proteins production.

Another study conduct evaluating the circadian rhythms of blood pressure and heart rate in normotensive and hypertensive rats exposed to Mozart or Ligeti music demonstrates that music of different character, like tempo, rhythms, pitch, tonality, can modify cardiovascular functions in freely-moving rats, with a more evident effect in hypertensive animals than in normotensive [60].

An enhancement of spatial-temporal reasoning performance after listening to Mozart's music for 10 minutes has been reported by several, but not all, researchers. Even in the studies with positive results the enhancement is small and lasts about 12 minutes. The effect varies between individuals and depends upon the spatial tasks chosen; general intelligence is not affected. Rather more impressively, there is a beneficial effect on some patients with epilepsy. The results are not specific to Mozart's compositions but the exact musical criteria required have not been completely defined.

\section{CONCLUSIONS}

According to some evidence, strategy of ME application could be able to ameliorate many conditions that to date negatively affect patients' quality of life and their social functioning. An allcomprehensive therapeutic approach could consider the helpful effects of ME in pain, mood, cardiovascular modifications, epilepsy and cognitive impairment.

More studies are needed, in order to define specific protocols in which music helps clinicians in recovering patients and in improving their quality of life.

\section{CONSENT}

It is not applicable.

\section{ETHICAL APPROVAL}

It is not applicable.

\section{COMPETING INTERESTS}

Authors have declared that no competing interests exist.

\section{REFERENCES}

1. Conard NJ, Malina M, Munzel SC. New flutes document the earliest musical tradition in Southwestern Germany. Macmillan Publishers Limited 2009;460. (DOI: 10.1038/nature08169)

2. Bradt J, Dileo C, Shim M. Music interventions for preoperative anxiety. Cochrane Database Syst Rev. 2013;6:CD006908.

\section{(DOI: 10.1002/14651858.CD006908)}

3. Conrad C, Niess H, Jauch KW, Bruns CJ, Hartl W, Welker L. Overture for growth hormone: Requiem for interleukin-6? Crit Care Med. 2007;35(12):2709-13.

4. Cacciafesta $M$, Ettorre $E$, Amici A, Cicconetti $P$, Martinelli V, Linguanti $A$, Baratta A, Verrusio W, Marigliano V. New frontiers of cognitive rehabilitation in geriatric age: The Mozart Effect (ME), Arch Gerontol Geriatr. 2010;51(3):79-82.

5. Trappe HJ. The effect of music on the cardiovascular system and cardiovascular health. Heart. 2010;96(23):1868-71.

6. Bradt J, Dileo C, Grocke D, Magill L. Music interventions for improving psychological and physical outcomes in cancer patients. Cochrane Database of Syst Rev, 2011;(8):CD006911.

7. Bodner M, Muftuler LT, Nalcioglu O, Shaw GL. FMRI study relevant to the Mozart effect: brain areas involved in spatialtemporal reasoning. Neurol. Res. 2001;23 (7):683-90.

8. Jausovec N, Habe K. The "Mozart effect": an electroencephalographic analysis employing the methods of induced event- 
related desynchronization/synchronization and event-related coherence. Brain Topogr. 2003;16(2):73-84.

9. Rauscher FH, Shaw GL, Ky KN. Music and spatial task performance. Nature. 1993;365(6447):611.

10. Steele KM. Arousal and mood factors in the "Mozart effect". Percept Mot Skills. 2000;91(1):188-90.

11. Hetland L. Listening to music enhances spatial-temporal reasoning: evidence for the "Mozart effect". Journal of Aesthetic Education. 2000;34(3-4):105-148.

12. Rauscher $\mathrm{FH}$, Robinson $\mathrm{KD}$, Jens JJ. Improved maze learning through early music exposure in rats. Neurol Res. 1998;20:427-432.

13. Aoun $\mathrm{P}$, Jones $\mathrm{T}$, Shaw $\mathrm{GL}$, Bodner $\mathrm{M}$. Long-term enhancement of maze learning in mice via a generalized Mozart effect. Neurol. Res. 2005;27:791-796.

14. Johnson JK, Cotman CW, Tasaki CS, Shaw GL. Enhancement of spatialtemporal reasoning after a Mozart listening condition in Alzheimer's disease: A case study. Neurol. Res. 1998;20:666-672.

15. Jausovec $\mathrm{N}$, Ksenija Jausovec, Ivan Gerlic. The influence of Mozart's music on brain activity in the process of learning. Clinical Neurophysiology. 2006;117:27032714.

16. Rauscher FH, Shaw GL, Ky KN. Listening to Mozart enhances spatial-temporal reasoning: towards a neurophysiological basis. Neurosci Lett. 1995;6;185(1):44-7.

17. Nakamura S, Norihiro Sadato, Tsutomu Oohashi, Emi Nishina, Yoshitaka Fuwamoto, Yoshiharu Yonekura. Analysis of music-brain interaction with simultaneous measurement of regional cerebral blood flow and electroencephalogram beta rhythm in human subjects. Neuroscience Letters. 1999;275:222-226.

18. Bodner M, Muftuler LT, Nalcioglu O, Shaw GL. FMRI study relevant to the Mozart effect: brain areas involved in spatialtemporal reasoning. Neurol. Res. 2001; 23(7):683-90.

19. Ho C, Mason O, Spence C. An investigation into the temporal dimension of the Mozart Effect: Evidence from the attentional blink task. Acta Psychol. 2007; 125(1):117-28.
20. Attanasio G, Cartocci G, Covelli E, Ambrosetti $\mathrm{E}$, Martinelli $\mathrm{V}$, Zaccone $\mathrm{M}$, Ponzanetti A, Gueli N, Filipo R, Cacciafesta M. The Mozart effect in patients suffering from tinnitus. Acta OtoLaryngologica. 2012;132(11):1172-7.

21. Salvatore $S$, Librando $A$, Esposito $M$, Vingolo EM. The Mozart effect in biofidback visual rehabilitation:a case report, Clinic Ophtalm. 2011;(5):1269-72.

22. Lubetzky R, Mimouni FB, Dollberg $\mathrm{S}$, Reifen R, Ashbel G, Mandel D. Effect of music by Mozart on energy expenditure in growing preterm infants. Pediatrics. 2010; 125(1):e24-8.

23. Lin LC, Lee WT, Wu HC, Tsai CL, Wei RC, Mok HK, Weng CF, Lee MW, Yang RC. The long-term effect of listening to Mozart K.448 decreases epileptiform discharges in children with epilepsy. Epilepsy Behav. 2011; 21(4):420-4.

24. Lin LC, Lee WT, Wang $\mathrm{CH}$, Chen $\mathrm{HL}, \mathrm{Wu}$ $\mathrm{HC}$, Tsai CL, Wei RC, Mok HK, Weng CF, Lee MW, Yang RC. Mozart K.448 acts as a potential add-on therapy in children with refractory epilepsy. Epilepsy Behav. 2011; 20(3):490-3.

25. Dastgheib SS, Layegh $P$, et al. The effects of Mozart's music on interictal activity in epileptic patients: Systematic review and meta-analysis of the literature. Current Neurology and Neuroscience Reports 14.1. 2014;1-11.

26. Hughes JR, Daaboul Y, Fino JJ, Shaw GL. The "Mozart effect" on epileptiform activity. Clin Electroencephalogr. 1998;29(3):10919.

27. Hughes JR. The Mozart effect. Epilepsy Behav. 2001;2(5):396-417.

28. Hughes JR. The Mozart Effect: Additional Data. Epilepsy Behav. 2002;3(2):182-184.

29. Hughes JR, Find JJ, Melyn MA. Is there a chronic change of the "Mozart effect" on epileptiform activity? A case study. Clin Electroencephalogr. 1999;30(2):44-5.

30. Fudin R, Lembessis E. The Mozart effect: questions about the seminal findings of Rauscher, Shaw, and colleagues Percept Mot Skills. 2004;98(2):389-405.

31. Steele KM, Brown JD, Stoecker JA. Failure to confirm the Rauscher and Shaw description of recovery of the Mozart effect. Percept Mot Skills. 1999;88:843-8. 
32. Steele KM, Bass KE, Crook MD. The mystery of the Mozart effect: Failure to replicate. Psychological Science. 1999;10: 4.

33. Pietschnig J, Voracek M, Formann AK. Mozart effect-Shmozart effect: A metaanalysis. Intelligence. 2010;38(3):314. (DOI: 10.1016/j.intell.2010.03.001)

34. Rideout BE. Performance suppression from control procedures is not the basis of the Mozart effect. Percept Mot Skills. 1999; 89(3 Pt 1):890.

35. McCutcheon LE. Another failure to generalize the Mozart effect. Psychol Rep. 2000;87(1):325-30.

36. Thompson WF, Schellenberg EG, Husain G. Arousal, mood, and the Mozart effect. Psychol Sci. 2001;12(3):248-51.

37. Twomey A, Esgate A. The Mozart effect may only be demonstrable in nonmusicians. Percept Mot Skills. 2002;95: 1013-26.

38. Giannouli V, Tsolaki M, Kargopoulos P. Psychiatrike. The influence of Mozart's and Beethoven's music on reverse mnemonic recall tasks. 2010;21(1):60-7.

39. Newman J, Rosenbach JH, Burns KL, Latimer BC, Matocha HR, Vogt ER. An experimental test of "the mozart effect": Does listening to his music improve spatial ability? Percept Mot Skills. 1995;81:137987.

40. Lints A, Gadbois S. Is listening to Mozart the only way to enhance spatial reasoning? Percept Mot Skills 2003;97: 1163-74.

41. Caldwell GN, Riby LM. The effects of music exposure and own genre preference on conscious and unconscious cognitive processes: A pilot ERP study. Conscious Cogn. 2007;16(4):992-6.

42. Gold BP, Frank MJ, Bogert B, Brattico E. Pleasurable music affects reinforcement learning according to the listener. Front Psychol. 201321;4:541.

(DOI: 10.3389/fpsyg.2013.00541)

43. Talero-Gutiérrez C, Zarruk-Serrano JG, Espinosa-Bode A. Musical perception and cognitive functions. Is there such a thing as the Mozart effect? Rev Neurol. 2004;1631;39(12):1167-73.

44. Bangerter A, Heath C. The Mozart effect: Tracking the evolution of a scientific legend. CBr J Soc Psychol. 2004;43:60523.

45. Leng $X$, Shaw GL. Towards a neural theory of higher brain function using music as a window, Concepts Neurosci. 1991;2: 229-258.

46. Frova A. Armonia celeste e dodecafonia. Musica e scienza attraverso i secoli. Bur Biblioteca Univ. Rizzoli; 2006.

47. Masataka N, Perlovsky L. Cognitive interference can be mitigated by consonant music and facilitated by dissonant music. Scientific Reports; 2013. Article number: 2028. (DOI: 10.1038/srep00694)

48. Perlovsky LI. A challenge to human evolution - cognitive dissonance. Front. Psychol. 2013;4:179.

(DOI: 10.3389/fpsyg.2013.00179)

49. Masataka N, Perlovsky L. The efficacy of musical emotions provoked by Mozart's music for the reconciliation of cognitive dissonance. Scientific Reports; 2012. Article number: 694.

(DOI: 10.1038/srep00694)

50. Perlovsky L, Cabanac A, Bonniot-Cabanac MC, Cabanac M. Mozart effect, cognitive dissonance, and the pleasure of music. Behav Brain Res. 2013;1;244:9-14.

(DOI: 10.1016/j.bbr.2013.01.036)

51. Tramo MJ, Cariani PA, Delgutte B, Braida LD. Neurobiological foundations for the theory of harmony in western tonal music. Ann. N. Y. Acad. Sci. 2001;930:92-116.

52. Hughes JR, Find JJ. The Mozart effect: distinctive aspects of the music-a clue to brain coding? Clin. Electroencephalogr. 2000;31:94-103.

53. Jenkins JS. The Mozart effect. J. R. Soc. Med. 2001;94:170-172.

54. Schlaug $G$. The brain of musicians. A model for functional and structural adaptation. Ann N Y Acad Sci. 2001;930: 281-99.

55. Schlaug G, Jäncke L, Huang Y, Steinmetz $\mathrm{H}$. In vivo evidence of structural brain asymmetry in musicians. Scienc. 1995; 267:699-701.

56. Schlaug G, Jäncke L, Huang Y, Staiger JF, Steinmetz $\mathrm{H}$. Increaded corpus callosum size in musicians. Neuropsychologia. 1995;33:1047-1055. 
57. Keenan JP, Thangaraj V, Halpern AR, Schlaug G. Absolute pitch and planum temporal. Neuroimag. 2001;14:1402-1408.

58. Gaser C, Schlaug G. Brain structures differ between musicians and non-musicians. J Neurosci. 2003;23(27):9240-5.

59. Fukui $\mathrm{H}$, Toyoshima K. Music facilitate the neurogenesis, regeneration and repair of neurons. Med Hypothese. 2008;71(5):7659.

60. Lemmer B. Effect of music composed by Mozart and Ligeti on blood pressure and heart rate circadian rhythms in normotensive and hypertensive rats. Chronobiol. Int. 2008;25(6):971-86.

(c) 2015 Verrusio et al.; This is an Open Access article distributed under the terms of the Creative Commons Attribution License (http://creativecommons.org/licenses/by/4.0), which permits unrestricted use, distribution, and reproduction in any medium, provided the original work is properly cited.

Peer-review history:

The peer review history for this paper can be accessed here: http://www.sciencedomain.org/review-history.php?iid=1120\&id=12\&aid=9307 